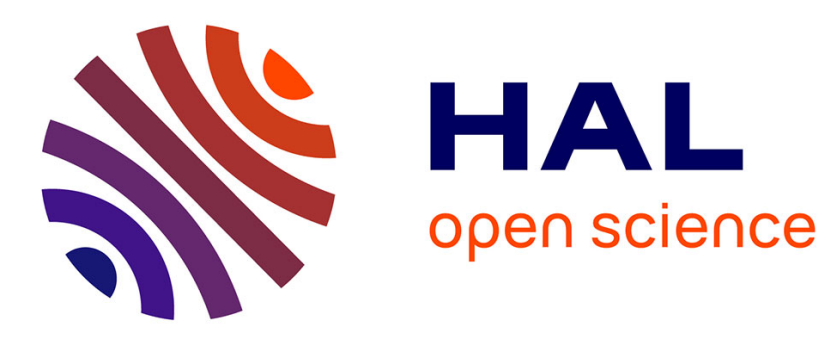

\title{
Modeling cyclic behavior of clay by micromechanical approach
}

Zhenyu Yin, Qiang Xu, Ching S. Chang

\section{To cite this version:}

Zhenyu Yin, Qiang Xu, Ching S. Chang. Modeling cyclic behavior of clay by micromechanical approach. Journal of Engineering Mechanics - ASCE, 2013, 139 (9), pp.1305-1309. 10.1061/(ASCE)EM.1943-7889.0000516 . hal-01007063

\section{HAL Id: hal-01007063 \\ https://hal.science/hal-01007063}

Submitted on 11 Mar 2018

HAL is a multi-disciplinary open access archive for the deposit and dissemination of scientific research documents, whether they are published or not. The documents may come from teaching and research institutions in France or abroad, or from public or private research centers.
L'archive ouverte pluridisciplinaire HAL, est destinée au dépôt et à la diffusion de documents scientifiques de niveau recherche, publiés ou non, émanant des établissements d'enseignement et de recherche français ou étrangers, des laboratoires publics ou privés. 


\title{
Modeling Cyclic Behavior of Clay by Micromechanical Approach
}

\author{
Zhen-Yu Yin ${ }^{1}$; Qiang Xu'; and Ching S. Chang, M.ASCE ${ }^{3}$
}

\begin{abstract}
Although stress-strain models for the cyclic behavior of clay have been studied extensively, the models have not been examined from the point of view of the intercluster contact level. In the current paper, we extend the recently developed micromechanical approach to model the cyclic behavior of clay. Undrained triaxial tests under one-way and two-way cyclic loadings on normally consolidated and overconsolidated clay are simulated to evaluate the applicability of the approach. The computed evolution of local stresses and local strains at intercluster scale due to exter-nally applied cyclic loads are also discussed.
\end{abstract}

Keywords: Cyclic loading; Micromechanics; Plasticity; Clay; Induced anisotropy; Stress reverse.

\section{Introduction}

Although stress-strain models for the cyclic behavior of clay have been studied extensively at the level of a soil element (e.g., Dafalias and Herrmann 1982; Wathugala and Desai 1993; Borja and Amies 1994; Bardet 1995; Li and Meissner 2002; Yu et al. 2007; and others), these models have not taken into account the behavior at the level of intercluster contact.

Chang et al. (2009) and Yin et al. (2009) have developed a micromechanical model for describing the behavior of clay under monotonic loading conditions. In this model, clay is considered as an assembly of clusters. The overall deformation is caused by the slip of clusters in all orientations. We have shown previously that because contact plane stresses are orientation dependent and intercluster properties are stress dependent, the model naturally exhibits the induced anisotropy (Yin and Chang 2009).

In this paper, modifications have been made on this micromechanical model to investigate the cyclic behavior of clay. Experimental results on clay are used for verification of this approach. The evolution of local stresses and local strains at the intercluster planes due to applied load are discussed. The overall applicability of the present model is evaluated based on the comparison of measured and predicted results.

\section{Modification of the Micromechanical Model}

In the basic model of Chang et al. (2009) and Yin et al. (2009), for the $\alpha$ th contact plane, we define a local normal stress, $\sigma^{\alpha}=f_{n}^{\alpha} N l / 3 V$, and a local shear stress, $\tau_{i}^{\alpha}=f_{r}^{\alpha} N l / 3 V$, where $l$ is the branch length and $N / V$ is the total number of contacts per unit volume. The corresponding local normal strain is defined as

${ }^{1}$ Professor, Dept. of Civil Engineering, Shanghai Jiao Tong Univ., Shanghai 200240, P.R. China; and Invited Professor, State Key Laboratory of Geohazard Prevention and Geoenvironment Protection, Chengdu Univ. of Technology, Chengdu 610059, P.R. China (corresponding author). E-mail: zhenyu.yin@gmail.com

${ }^{2}$ Professor, State Key Laboratory of Geohazard Prevention and Geoenvironment Protection, Chengdu Univ. of Technology, Chengdu 610059, P.R. China. E-mail: xq@cdut.edu.cn

${ }^{3}$ Professor, Dept. of Civil and Environmental Engineering, Univ. of Massachusetts, Amherst, MA 01002. E-mail: chang@ecs.umass.edu $\varepsilon^{\alpha}=\delta_{n}^{\alpha} / l$ and a local shear strain is defined as $\gamma_{i}^{\alpha}=\delta_{r}^{\alpha} / l$. With these definitions, applying a static hypothesis for an isotropic material, the local stress and overall stress are determined by $\tau_{i}^{\alpha}=\sigma_{i j} n_{j}$, and the local strain and overall strain are determined by $\gamma_{i}^{\alpha}=\varepsilon_{i j} n_{j}$.

The details of the micromechanical model can be found in Chang et al. (2009), and are not repeated here. To simulate cyclic loadings, the shear reversal must be considered for the contact plane between two clusters. For this purpose, a shear reversal model (Yin and Chang 2009) is adopted, and in this paper, we present only the major modification of the model.

The undrained cyclic test includes a consolidation stage and an undrained cyclic stage. At the consolidation stage up to a maximum mean effective stress, each contact plane reaches a maximum local normal stress $\sigma^{\alpha}{ }_{\max }$. During the unloading portion of cyclic loading, at each contact plane, the local normal stress $\sigma^{\alpha}$ reduces; thus, the local overconsolidation ratio (OCR) (i.e., the ratio of the past maximum normal contact stress $\sigma^{\alpha}{ }_{\max }$ and the current normal contact stress $\sigma^{\alpha}$ ) increases continuously. To describe the cyclic behavior of clay, the local OCR accounting for the effect of stress history at the contact level is considered in the modified version. As the local OCR increases, the plastic stiffness on the contact plane increases, and the constant $k_{p R}^{\alpha}$ is assumed to be proportional to the local OCR, given by

$$
k_{p R}^{\alpha}=k_{p R 0} \frac{\sigma_{\max }^{\alpha}}{\sigma^{\alpha}}
$$

If this modification at the contact level is applied to the plastic stiffness, the stress history effect on the stress-strain of the assemblies can be reproduced, which will be shown subsequently.

This modification does not increase the number of input parameters. In the current version, the value $n=1$ in the expression of intercluster stiffness $k_{n}^{\alpha}=k_{n 0}\left(\sigma^{\alpha} / p_{\text {ref }}\right)^{n}$ is typically assumed for clay based on the rebounded slope $\kappa$ of the isotropic compression test. The normal stiffness $k_{n 0}$ is determined from: $k_{n 0}$ $=9\left(1+e_{0}\right) p_{\text {ref }} /(4 \kappa)$ (Chang et al. 2009). The value of $k_{r R}$ is related to Poisson's ratio, and a value of 0.5 is generally assumed for clay. The compression coefficient $c_{p}$ is determined from the compression index $\lambda$ and the rebound index $\kappa$ using the equation $c_{p}=(\lambda-\kappa) /\left(3+3 e_{0}\right)$ (Chang et al. 2009). For simplicity, 

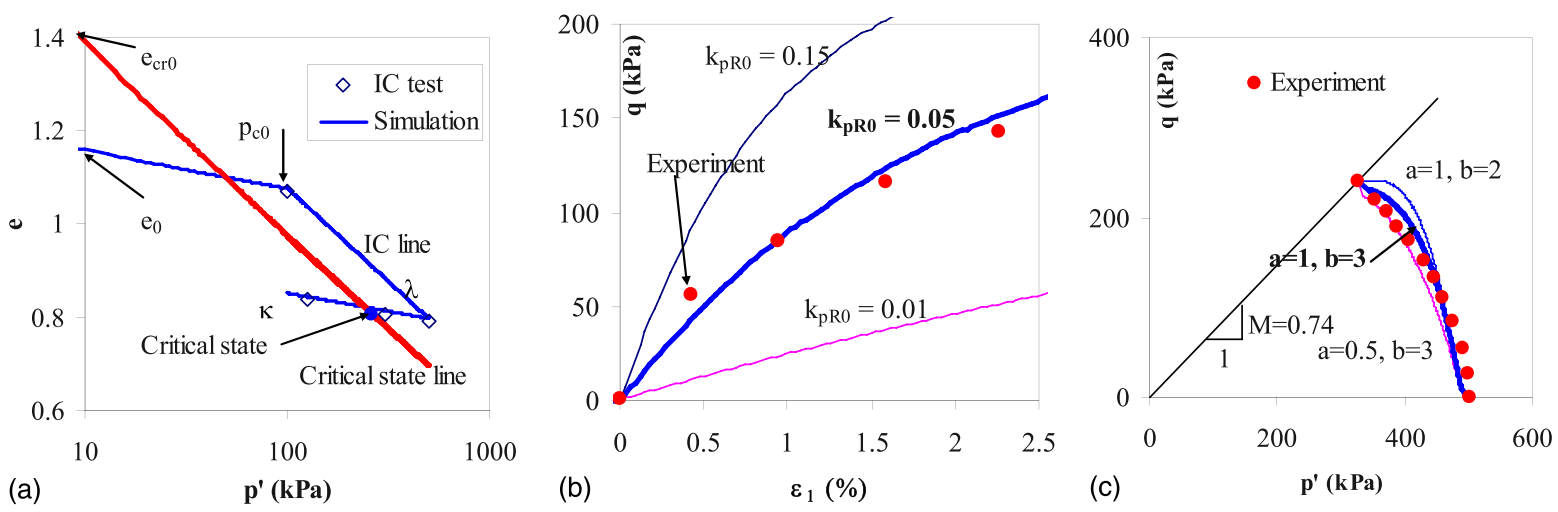

Fig. 1. Calibration of parameters from tests

the parameters $\kappa$ and $\lambda$ are used instead of $k_{n 0}$ and $c_{p}$ in the current paper.

\section{Experimental Verifications}

\section{Review of Experimental Results}

The experimental verification is presented herein with reference to the undrained tests under monotonic and cyclic loading on a commercially available clay by Li and Meissner (2002). Conventional triaxial tests were conducted on soil samples, which were reconsolidated isotropically with $\mathrm{OCR}=1.0,1.6$, and 4.0 for monotonic loading and $\mathrm{OCR}=1.0$ and 5.1 for cyclic loading. All cyclic tests were stress controlled, using the sinusoidal wave form and a wave frequency of $0.1 \mathrm{~Hz}$.

\section{Calibration of Model Parameters}

One undrained triaxial compression test with $\mathrm{OCR}=1$ and one isotropic consolidation test were needed for the calibration of model parameters, as shown in Fig. 1. Fig. 1(a) was constructed from experimental data $\left(e_{0}, e_{c r 0}, \kappa\right.$, and $\left.\lambda\right)$ provided by Li and Meissner (2002) assuming $\sigma_{p c 0}=100 \mathrm{kPa}$ for the convenience of parameter determination. The internal friction angle $\phi_{\mu}=19.2^{\circ}$ was obtained from the undrained triaxial test corresponding to $M=0.74$ [Fig. 1(c)]. Other parameters were obtained by curve fitting: (1) the shear hardening parameter $k_{p R 0}$ was determined from the $q-\varepsilon_{1}$ curve of the undrained compression test within the small strain level [Fig. 1(b)], and (2) the dilatancy constants $a$ and $b$ were determined from the effective stress path of the undrained compression test [Fig. 1(c)]. All parameters are summarized in Table 1. Note that for the undrained triaxial test, the simulation was carried out keeping constant volume [i.e., through the strain control with $d \varepsilon_{v}=0$ (i.e., $d \varepsilon_{a}=-2 d \varepsilon_{r}$ )], and the excess pore pressure was obtained from the difference between the total mean stress $\left(p=p_{0}+\Delta q / 3\right)$ and the mean effective stress.

The determined parameters were used to simulate monotonic undrained triaxial tests on samples with different OCRs. As shown in Figs. 2( $\mathrm{a}$ and $\mathrm{b}$ ), the model predictions considering the OCR effect of local plastic stiffness [as shown in Eq. (1)] agree well with the experimental results.

Parameters determined from monotonic tests were used to simulate undrained tests under cyclic loadings. It is worth noting that the initial slopes of the $q-\varepsilon_{d}$ curves for monotonic and one- and two-way cyclic tests were very different from each other, mainly because of the loading rate effect and sample variations. It seemed reasonable to
Table 1. Values of Parameters for Tested Clay

\begin{tabular}{|c|c|c|c|c|c|c|c|}
\hline$e_{0}$ & $\kappa$ & $\lambda$ & $e_{c r 0}$ & $a$ & $b$ & $\phi_{\mu}^{\prime}\left({ }^{\circ}\right)$ & $k_{p R 0}$ \\
\hline 1.16 & 0.034 & 0.173 & 1.39 & 1 & 3 & 19.2 & $0.05^{\mathrm{a}}$ \\
\hline
\end{tabular}

use different sets of parameters for simulating tests with different loading rates (Li and Meissner 2002; Yu et al. 2007). In the following simulation, only different values of $k_{p R}$ were selected for each case: $k_{p R 0}=0.24$ for a one-way test with OCR $=1, k_{p R 0}=0.12$ for a oneway test with $\mathrm{OCR}=5.1, k_{p R 0}=0.9$ for a two-way test with $\mathrm{OCR}=1$, and $k_{p R 0}=0.27$ for a two-way test with $\mathrm{OCR}=5.1$.

\section{Comparison of Predicted and Measured Behavior}

\section{Normal Consolidated Soil}

Figs. 3 and 4 show the comparison between the experimental and numerical results for undrained triaxial tests under one-way and twoway cyclic loadings, respectively, for clay samples with OCR $=1$. Although the clay sample had an initial $\mathrm{OCR}=1$, because of pore pressure development, the OCR continued to increase; thus, the value of the local plastic stiffness continued to increase during the test [Eq. (1)]. In these figures, the deviatoric stress $q$ was plotted against the deviatoric strain $\varepsilon_{q}$ [Figs. 3(a and c) and 4(a and c)] and the pore pressure $(\Delta u)$ was plotted against the number of cycles [Figs. 3(b and d) and 4(b and d)]. Comparisons in Figs. 3 and 4 demonstrate that the model that considered the OCR effect on plastic stiffness captured the cyclic behaviors on both the stress-strain curve and pore pressure versus the number of cycles for both cases of oneway and two-way cyclic loadings.

\section{Overconsolidated Soil}

Simulations were also carried out for tests under one-way and twoway loadings on overconsolidated samples $(\mathrm{OCR}=5.1)$, as shown in Figs. 5 and 6. Because only the measured pore pressure versus the number of cycles was available, it was compared with model simulations. Comparisons in Figs. 5 and 6 show the trend of pore water pressure that decreased during both one-way and two-way cyclic loadings for overconsolidated clay.

In general, the micromechanics-based model was able to describe the undrained behavior of clay subjected to one- and two-way cyclic-loading conditions.

\section{Micromechanical Analysis for Induced Anisotropy}

Because local stresses are contact orientation dependent, we selected the orientation distributions for local stresses and strains to 

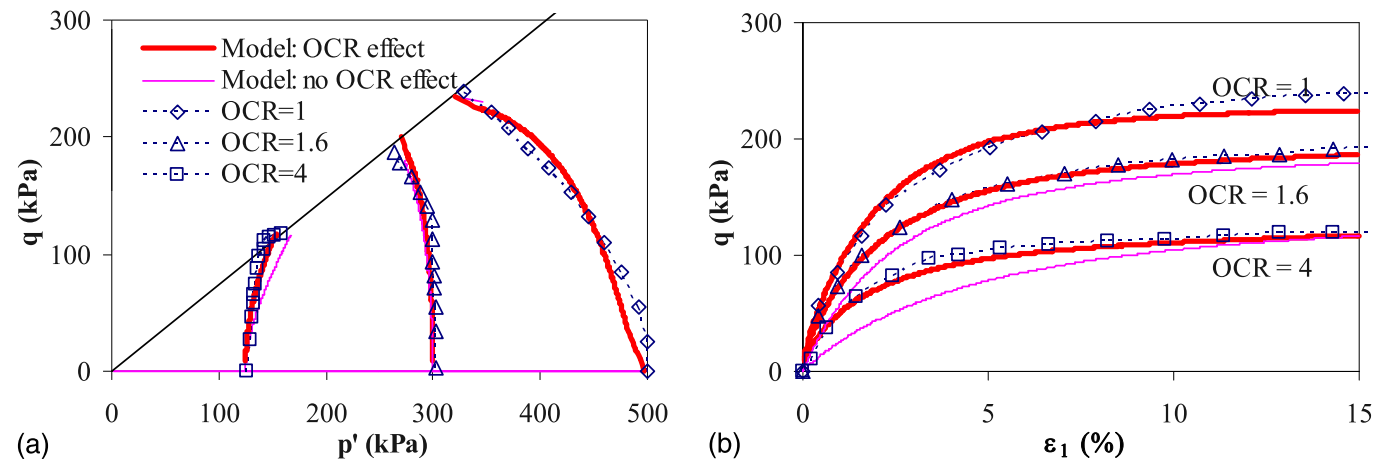

Fig. 2. Comparison between experimental results and simulations for undrained triaxial tests under monotonic loading
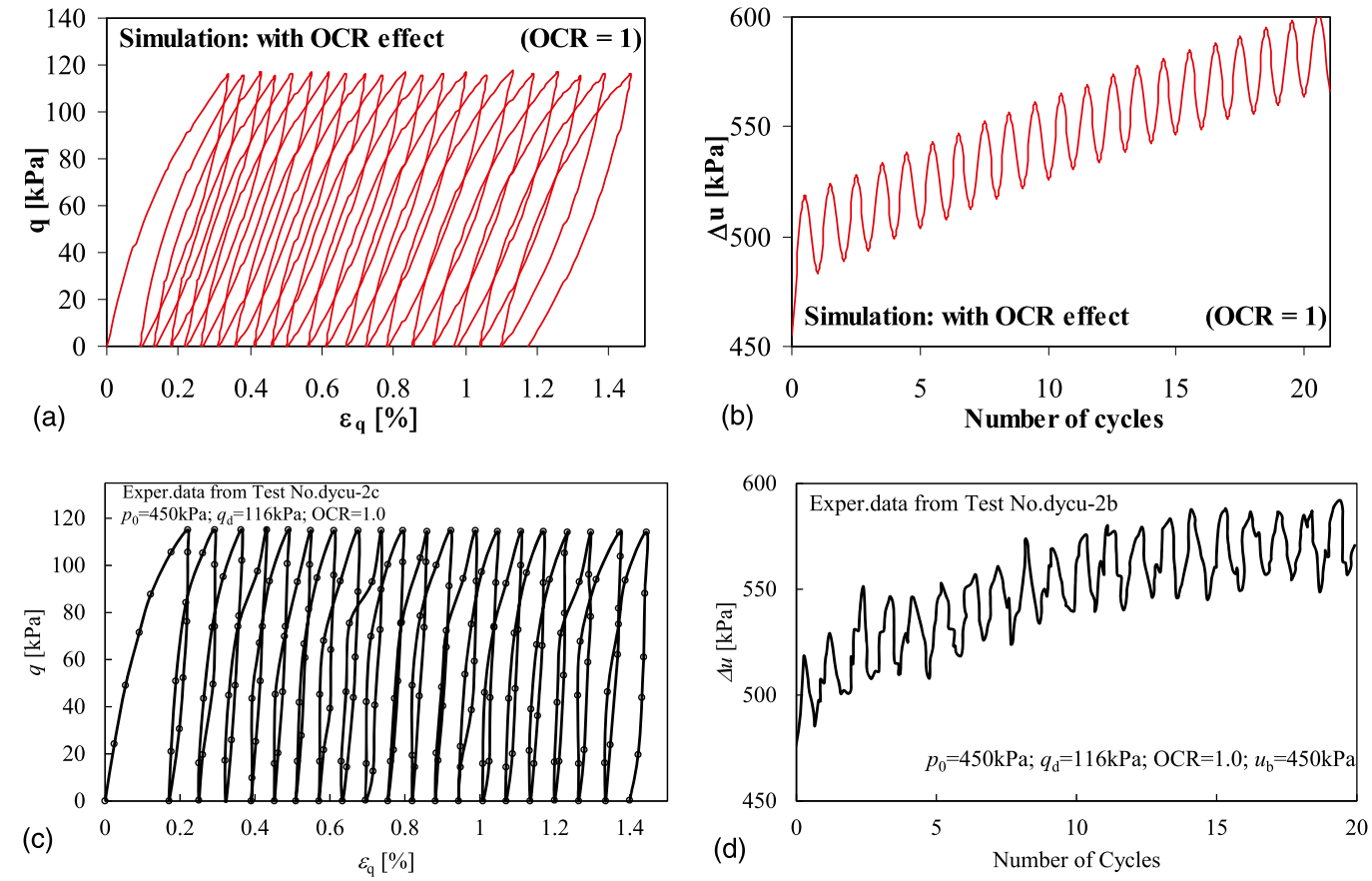

Fig. 3. Comparison between experimental and numerical results for undrained triaxial tests under one-way cyclic loading $(\mathrm{OCR}=1)$

investigate the induced anisotropic behavior during undrained cyclic loading. The one-way cyclic test on the normally consolidated sample was selected for the investigation, with selected loading steps marked by empty circles (see Fig. 7).

Fig. 8(a) gives the initial orientation distributions of normal stress $\sigma_{n}$, where the axes of anisotropy of the soil were coaxial to the axes of loading stresses. Initially [Step 0 in Fig. 8(a)], the circular shape implies an isotropic distribution of normal stresses and the properties associated with the normal stresses (e.g., elastic modulus, plastic modulus). During the first loading [Step 1 in Fig. 8(a)], the axis in the vertical direction becomes longer because of the applied vertical load, which indicates that the stress-dependent soil properties are also changed in the same pattern. For Step 2 in Fig. 8(a), the ovalshape distribution of normal stresses becomes smaller because of the increase of pore pressure during undrained cyclic loading, but the long axis stays in the vertical direction. At Step 3, when the stress is back to an isotropic state $(q=0)$, the shape of distribution changes back to circular. In the current model, the stresses on each plane are considered to be internal state variables, and their evolution leads to the behavior change on each individual plane; thus, the resulting behavior naturally exhibits the stress-induced anisotropy.

The distribution of shear stress ratio $\tau / \sigma$, shown in Fig. 8(b), expands from zero to Step 1 for first loading. Followed by repeated loading cycles, the local stress ratio continues to increase up to Step 2 because of the significant decrease in normal stress $\sigma_{n}$ for some orientations.

The distribution of normal strain $\varepsilon$, shown in Fig. 8(c), at the end of the isotropic consolidation, is plotted as the bold line as a reference for the following steps. During the first loading, the branch lengths shorten (i.e., compress) significantly for contact planes with $0^{\circ}<\alpha<45^{\circ}$, but they elongate for contact planes with $45^{\circ}<\alpha$ $<90^{\circ}$ because of the combination of shear-induced dilation and normal stress reduction. The distribution changes from Step 1 to Step 2 due to the accumulation of local strains during load cycles. Step $3(q=0)$ represents the permanent strains after 20 repeated load cycles.

The distribution of shear strain $\gamma$ in Fig. 8(d) shows that large shear strains occurred because of repeated loading for 

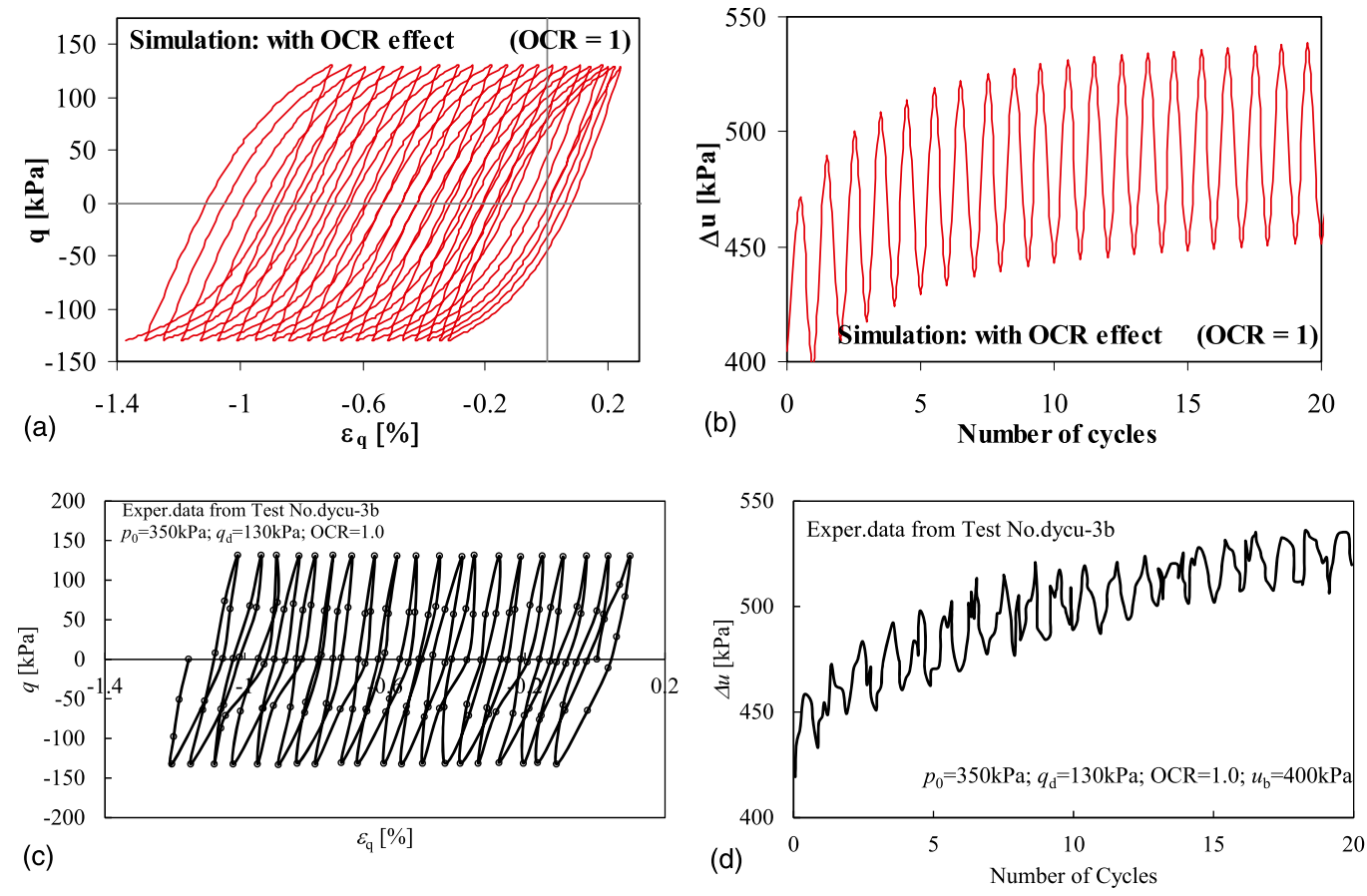

Fig. 4. Comparison between experimental and numerical results for undrained triaxial tests under two-way cyclic loading $(\mathrm{OCR}=1)$

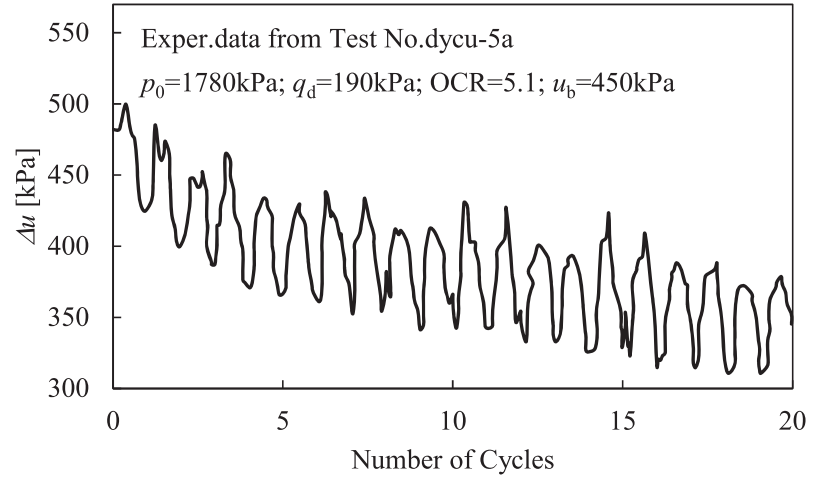

Fig. 5. Comparison between experimental and numerical results for undrained triaxial tests under one-way cyclic loading $(\mathrm{OCR}=5.1)$

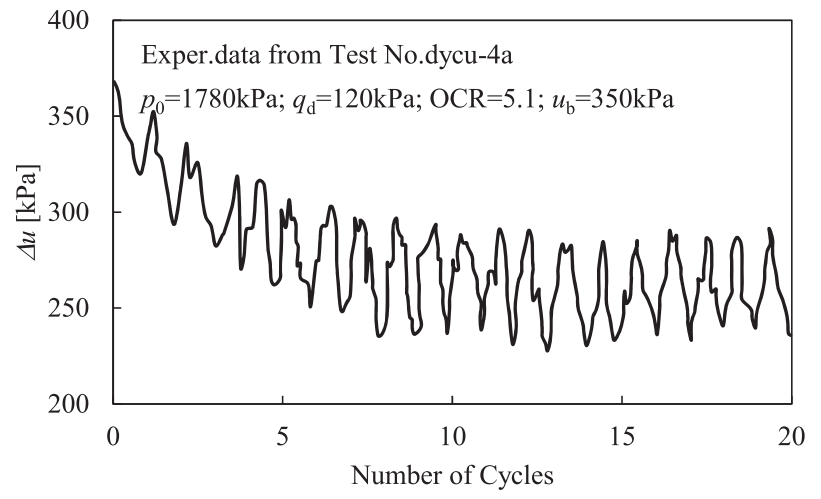

Fig. 6. Comparison between experimental and numerical results for undrained triaxial tests under two-way cyclic loading $(\mathrm{OCR}=5.1)$

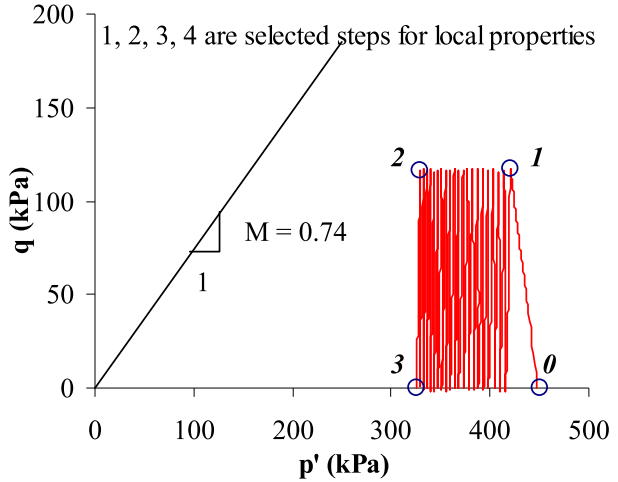

Fig. 7. Seven interparticle orientations located on the $x$-z plane of the coordinate system

the contact planes near the orientation of $55^{\circ}$ (at Steps 1 and 2). The distribution of Step 3 also represents the permanent local shear strains for different contact planes after 20 cycles of loading.

\section{Conclusions}

The previous micromechanical stress-strain model has been enhanced by considering the stress history effect on the local stress-strain behavior at the contact level. Undrained triaxial tests on samples with different OCRs subjected to monotonic and cyclic loadings were simulated by the enhanced model. Good agreement was achieved between the experimental results and the simulations. The opposing behavior of pore pressure generation (i.e., increase in pore pressure for $\mathrm{OCR}=1$ and decrease in pore pressure for $\mathrm{OCR}=5$ ) is captured by the current model. The local OCR effect on the plastic stiffness at the contact planes improves the simulation performance. 


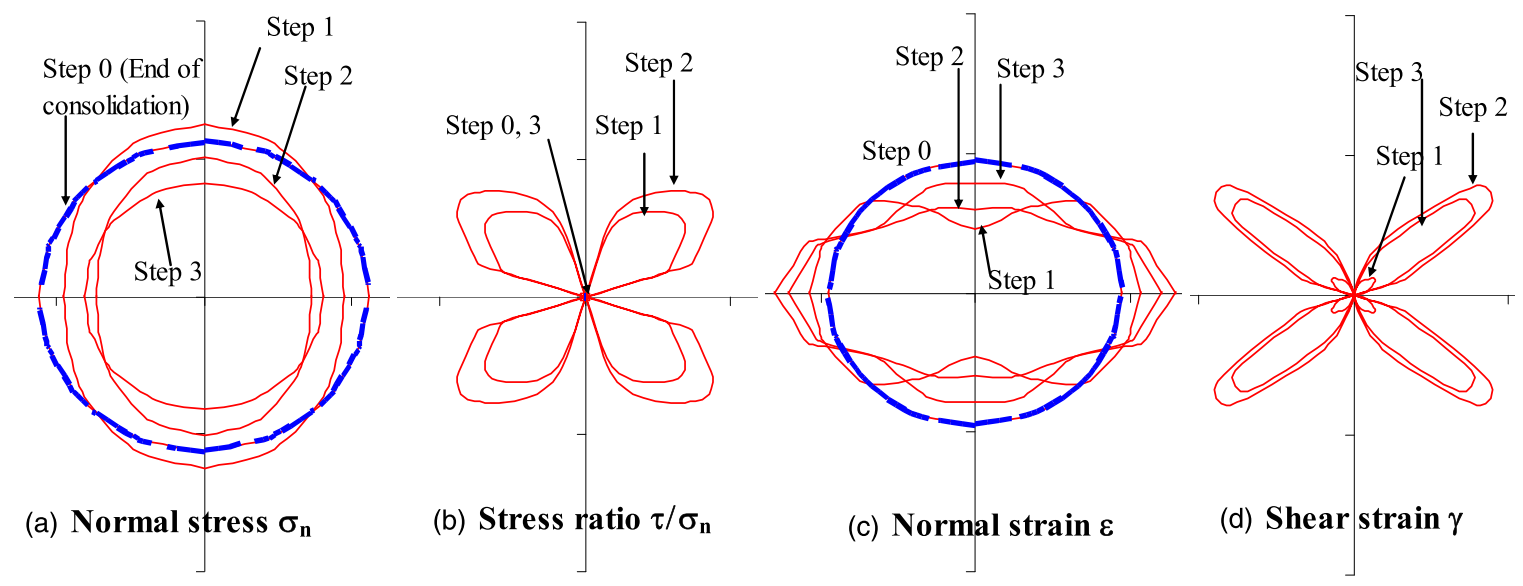

Fig. 8. Orientational distribution of local stress-strains during one-way cyclic loading: (a) normal stress; (b) stress ratio; (c) normal strain; and (d) shear strain

The predicted behavior at interparticle contact planes was examined for an undrained triaxial test under one-way cyclic loading. It was shown from the rose diagrams that the contact stress distribution changes throughout the triaxial test, which implies the development of anisotropy induced by the externally applied load, because the elastic modulus and plastic modulus on each contact plane are stress dependent. The permanent strains on every contact plane are developed at different magnitudes. Active contact planes on a few orientations contribute greatly to the permanent deformation of the assembly. Therefore, the local strains are highly nonuniform, as are also demonstrated by rose diagrams.

Model predictions for undrained cyclic tests on clay have demonstrated that the present micromechanical approach is capable of modeling undrained cyclic behavior, taking into consideration stress-induced anisotropy.

\section{Acknowledgments}

This research was supported financially by the opening project of the State Key Laboratory of Geohazard Prevention and Geoenvironment Protection (Grant No. SKLGP2011K013), the Research Fund for the Doctoral Program of Higher Education of China (Grant No. 20110073120012), the National Natural Science Foundation of China (Grant No. 41240024), and the Shanghai Pujiang Talent Plan (Grant No. 11PJ1405700).

\section{References}

Bardet, J. P. (1995). "Scaled memory model for undrained behavior of anisotropic clays." J. Geotech. Engrg., 121(11), 755-765.

Borja, R. I., and Amies, A. P. (1994). "Multiaxial cyclic plasticity model for clays." J. Geotech. Engrg., 120(6), 1051-1070.

Chang, C. S., Hicher, P.-Y., Yin, Z.-Y., and Kong, L.-R. (2009). "Elastoplastic model for clay with microstructural consideration." J. Eng. Mech., 135(9), 917-931.

Dafalias, Y. F., and Herrmann, L. R. (1982). "Bounding surface formulation of soil plasticity." Soil mechanics-transient and cyclic loads, G. N. Pande and D. C. Zienkiewicz, eds., Wiley, New York, 253-282.

Li, T., and Meissner, H. (2002). "Two-surface plasticity model for cyclic undrained behavior of clays." J. Geotech. Geoenviron. Eng., 128(7), 613-626.

Wathugala, G. W., and Desai, C. S. (1993). "Constitutive model for cyclic behavior of clays I: Theory.” J. Geotech. Engrg., 119(4), 714-729.

Yin, Z.-Y., and Chang, C. S. (2009). "Microstructural modelling of stress-dependent behaviour of clay." Int. J. Solids Struct., 46(6), $1373-1388$.

Yin, Z.-Y., Chang, C. S., Hicher, P. Y., and Karstunen, M. (2009). "Micromechanical analysis of kinematic hardening in natural clay." Int. J. Plast., 25(8), 1413-1435.

Yu, H.-S., Khong, C., and Wang, J. (2007). "A unified plasticity model for cyclic behaviour of clay and sand." Mech. Res. Commun., 34(2), 97-114. 